\title{
Investigation of antioxidative effects of a cardioprotective solution in heart tissue
}

\author{
Miriam Russ $^{1} \cdot$ Susanne Jauk ${ }^{1} \cdot$ Reinhold Wintersteiger $^{1} \cdot$ Michaela Andrä $^{2} \cdot$ Iva $^{B_{\text {Bcic }}}{ }^{3} \cdot$ Astrid Ortner $^{1}$
}

Received: 18 January 2019 / Accepted: 15 July 2019 / Published online: 24 July 2019

(c) The Author(s) 2019

\begin{abstract}
A multi-component solution, containing $\alpha$-ketoglutaric acid $(\alpha-\mathrm{KG})$, 5-hydroxymethylfurfural (5-HMF), $N$-acetyl-selenoL-methionine (NASeLM), and $N$-acetyl-L-methionine (NALM) as active ingredients, has been tested considering its supposed antioxidative effect with respect to heart transplantations. Oxidative stress was induced on isolated rat hearts through occlusion of a coronary artery and in chicken heart tissue through hydrogen peroxide. Both heart types were analyzed and the oxidative stress markers malondialdehyde (MDA) and carbonyl proteins (CPs) were determined via HPLC/UV-Vis. In both approaches, it was found that treatment with the multi-component solution led to a lower amount of MDA and CPs compared to a negative control treated with Krebs-Ringer solution (KRS). Further investigation on chicken heart tissue identified $\alpha-K G$ as antioxidative component in these experiments. However, numerous factors like arrhythmia, vessel dilatation, and minimization of oxidative stress effects play an important role for successful transplantation. Therefore, the investigated multi-component solution might be a novel approach against oxidative stress situations, for example at ischemia reperfusion injury during heart transplantations.
\end{abstract}

Keywords Malondialdehyde · Carbonyl proteins · Alpha-ketoglutarate $(\alpha-K G) \cdot$ HPLC/UV-Vis · Ischemia reperfusion . Oxidative stress

\section{Introduction}

Graft failure is a severe problem after heart transplantations. It is caused due to the excessive formation of reactive oxygen and nitrogen species (ROS/RNS) during the peri-surgical process including explantation, transport, and implantation.

ROS generation occurs mainly at reperfusion when molecular oxygen is reintroduced into the ischemic area. Furthermore, ROS can react with nitric oxide (NO) and thereby form reactive nitrogen species (RNS) - for example peroxynitrite $[1,2]$. ROS and RNS are able to cause

Astrid Ortner

astrid.ortner@uni-graz.at

1 Department of Pharmaceutical Chemistry, Institute of Pharmaceutical Sciences, University of Graz, Schubertstraße 1, 8010 Graz, Austria

2 Division of Transplant Surgery, Medical University of Graz, Auenbruggerplatz 29, 8036 Graz, Austria

3 Diagnostic \& Research Institute of Pathology, Medical University of Graz, Neue Stiftingtalstraße 6, 8010 Graz, Austria genotoxic damage, cell dysfunction, and cell death or inactivation of enzymes by oxidizing structures such as proteins, lipids, and DNA, resulting in oxidative tissue damage [3, 4]. Overall, these effects can lead to a functional disorder of the transplanted organ in the body and result in graft failure [1]. Therefore, it is important in transplant surgery to reduce or block the effect of ROS and RNS and their following ischemia reperfusion injury to avoid this malfunction.

A novel approach to overcome this problem is a multicomponent solution in combination with angiotensin-(1-7). The active ingredients of the multi-component solution are $\alpha$-ketoglutaric acid $(\alpha-\mathrm{KG}), 5$-hydroxymethylfurfural (5-HMF), $N$-acetyl-seleno-L-methionine (NASeLM), and $\mathrm{N}$-acetyl-L-methionine (NALM). $\alpha-\mathrm{KG}$ and 5-HMF are described as directly antioxidative agents under different conditions [5-8]. NALM is a source of methionine, while NASeLM is a source of selenium. Both methionine and selenium are contributors of the body's antioxidative defense system via regulation of antioxidative enzymes [9-12].

The combination showed already promising effects on the hearts of male Wistar rats at the Langendorff device considering arrhythmia, coronary flow, etc. during ischemia [13]. 
Angiotensin 1-7 has already been studied and proven to have antiarrhythmic and cardioprotective effects [14-16].

It was hypothesized that the multi-component solution exhibits significant antioxidative power in heart tissue, which is considered to be effective against ROS and RNS, thereby minimizing ischemia reperfusion injury. Hence, the aim of this study was to investigate the supposed antioxidative effect of the multi-component solution via the oxidative stress markers malondialdehyde (MDA) and carbonyl proteins (CPs). MDA as result of lipid peroxidation and CPs as result of protein oxidation are both stable products and reflect the local occurrence of ROS. They are widely applied markers for the determination of oxidative stress [17].

Simulation of oxidative stress was carried out by applying two different approaches: via myocardial infarction on the hearts of male Wistar rats and via oxidation of chicken heart tissue through hydrogen peroxide. Krebs-Ringer solution was used as negative control during experiments. MDA and CPs were quantified in the heart tissue with HPLC according to a formerly developed method [18].

\section{Materials and methods}

\section{Reagents and chemicals}

All reagents and chemicals were of analytical grade and applied without further purification. HPLC-grade deionized water was used during all experiments.

$\alpha-K G, 5-H M F$, NASeLM, NALM, and glucose were supplied by CYL-Pharma (Lassnitzhöhe, Austria). NaCl, $\mathrm{KCl}, \mathrm{KH}_{2} \mathrm{PO}_{4}, \mathrm{MgSO}_{4}, \mathrm{CaCl}_{2}, \mathrm{NaHCO}_{3}$, and dextrose were obtained from Roth (Karlsruhe, Germany). Acetonitrile, ammonium acetate, 1-butanol, ethanol, HPLC-grade water, hydrogen peroxide, and $\mathrm{HCl}$ were obtained from Merck (Darmstadt, Germany). Albumin from human serum, angiotensin 1-7 acetate salt hydrate, butylated hydroxytoluene (BHT), 2,4-dinitrophenylhydrazine (DNPH), ethyl acetate, guanidine-hydrochloride, malondialdehyde tetra-butylammonium salt (MDA), 2-thiobarbituric acid (TBA), trichloroacetic acid (TCA), and tris(hydroxymethyl)aminomethane (Tris) were obtained from Sigma-Aldrich (Vienna, Austria).

\section{Animals}

Three-month-old male Wistar rats, with a weight between 300 and $450 \mathrm{~g}$, were obtained from Medical University of Vienna (Department of Biomedical Research). The animals were kept according to the Austrian animal welfare act. They were housed in a room with a temperature between 20 and $24{ }^{\circ} \mathrm{C}, 55 \% \pm 10 \%$ relative humidity, and a $12 \mathrm{~h}$ light/ $12 \mathrm{~h}$ dark cycle. Animal experiments were conducted in compliance with the Austrian law on experimentation with laboratory animals. The health of the animals was periodically checked and high hygienic standards were strictly observed. Chicken hearts were obtained from a slaughterhouse.

\section{Apparatus}

During the warm ischemia experiments on rat hearts, an IH-5 Langendorff device from Harvard Apparatus and the HSE-isoheart software were applied.

For both rat and chicken hearts, HPLC analysis was carried out with an Agilent Technologies 1260 Infinity Quat Pump VL and a Merck-Hitachi LaChrom L-7400 UVdetector. A LiChroCart ${ }^{\circledR}$ RP-18 endcapped ( $\left.5 \mu \mathrm{m}\right)$ column (250-4) and a mobile phase containing $100 \mathrm{mM}$ ammonium acetate buffer $(100 \mathrm{mM})$ and acetonitrile $(50+50(\mathrm{v} / \mathrm{v}))$ were applied with a flow of $1 \mathrm{~mL} / \mathrm{min}$. Samples were injected via a $100-\mu \mathrm{L}$ loop and detected at a wavelength of $370 \mathrm{~nm}$ or $532 \mathrm{~nm}$. Peak areas were evaluated with the Agilent ChemStation Software.

\section{Preparation of applied solutions}

For all experiments, Krebs-Ringer solution (KRS) was used as control solution (negative control). Krebs-Ringer stock solution was composed of $2.37 \mathrm{M} \mathrm{NaCl}, 0.094 \mathrm{M} \mathrm{KCl}$, $0.024 \mathrm{M} \mathrm{KH}_{2} \mathrm{PO}_{4}, 0.023 \mathrm{M} \mathrm{MgSO}_{4}$, and $0.05 \mathrm{M} \mathrm{CaCl}_{2}$. $100 \mathrm{~mL}$ of this stock solution, $0.05 \mathrm{M} \mathrm{NaHCO}_{3}, 0.023 \mathrm{M}$ dextrose, and water ad $2 \mathrm{~L}$ were mixed to get KRS.

To obtain the multi-component solution $62 \mathrm{mM} \alpha-\mathrm{KG}$, $24 \mathrm{mM}$ 5-HMF, $0.5 \mathrm{mM}$ NALM, and $0.008 \mathrm{mM}$ NaSeLM as effective ingredients and $166 \mathrm{mM}$ glucose were dissolved in water. The ratio of each component has been selected based on preliminary investigations with regard to pharmacological adverse effects. The $\mathrm{pH}$ of the final solution was adjusted to 5.7 with $0.1 \mathrm{M} \mathrm{NaOH}$.

For Langendorff experiments, a dilution of the multi-component solution with KRS $(20+80 ; \mathrm{v} / \mathrm{v})$-further referred to as D20 - was prepared. For physiological reasons, the tested solutions (D20, KRS) contained $0.02 \%$ albumin.

For chicken heart experiments, pure multi-component solution, KRS, and dilutions of the multi-component solution with KRS at the ratios $40+60$ and $10+90$ were applied. All tested solutions were mixed with $10 \%$ hydrogen peroxide $1+1(\mathrm{v} / \mathrm{v})$ for oxidative stress simulation or with water $1+1$ (v/v) as basal value. Thus, the final investigated dilutions resulted in the concentrations of 50\% (D50), 20\% (D20), and 5\% (D5). For single ingredient experiments, solutions with just one ingredient were prepared with the same concentration of the ingredient as in the pure multi-component solution. Each substance was dissolved in water and adjusted to $\mathrm{pH} 5.7$ with $0.1 \mathrm{M} \mathrm{NaOH} / 0.1 \mathrm{M} \mathrm{HCl}$. The solutions were 
mixed $1+1(\mathrm{v} / \mathrm{v})$ with $10 \%$ hydrogen peroxide or water, resulting in a final concentration as in D50.

All solutions were filtered through a $0.45-\mu \mathrm{m}$ membrane and stored at $4{ }^{\circ} \mathrm{C}$ in the refrigerator.

\section{Treatment of isolated rat hearts}

Rats were anaesthetized with ketamine s.c. ( $70-100 \mathrm{mg} / \mathrm{kg}$ ). The heart was removed quickly, immediately placed in icecold KRS (pH 7.4), and cannulated onto the Langendorff apparatus via aorta. The retrograde perfusion pressure was maintained at $70 \mathrm{mmHg} \pm 10 \mathrm{mmHg}$. The perfusion solutions were warmed at $37^{\circ} \mathrm{C} \pm 1{ }^{\circ} \mathrm{C}$ and infused continuously with $95 \% \mathrm{O}_{2}+5 \% \mathrm{CO}_{2}$ throughout the experiment.

All hearts were purged with pure KRS during the stabilization period. After $35 \mathrm{~min}$, the therapy period started by using D20 or remaining with KRS. After 10 min of therapy, warm ischemia was established for $15 \mathrm{~min}$ by occlusion of a coronary artery, followed by reperfusion for $30 \mathrm{~min}$. The experiment was finished after $90 \mathrm{~min}$. Figure 1 shows the experimental design via a typical coronary flow alteration. For non-oxidized hearts, no occlusion (=no ischemia) was established in order to get basal values for comparison.

At the end of the experiment, every single heart was divided into two parts. One part was blast-frozen with liquid nitrogen and stored at $-80{ }^{\circ} \mathrm{C}$ until investigation of oxidative stress markers. The other part was stored in formalin and used for histological and immunohistochemical analysis.

\section{Treatment of chicken hearts}

Chicken hearts were prepared as described by Russ et al. [18]. Briefly, the hearts were sliced into $0.5 \mathrm{~cm}$ pieces. $2 \mathrm{~g}$ quantities of those were incubated in each $10 \mathrm{~mL}$ of oxidizing solution for $60 \mathrm{~min}$. For non-oxidized values the solutions were mixed with water instead of hydrogen peroxide in order to get basal values for better comparison. Afterward the solutions were decanted and the remaining tissue was washed twice with water. Finally, the heart tissue was frozen

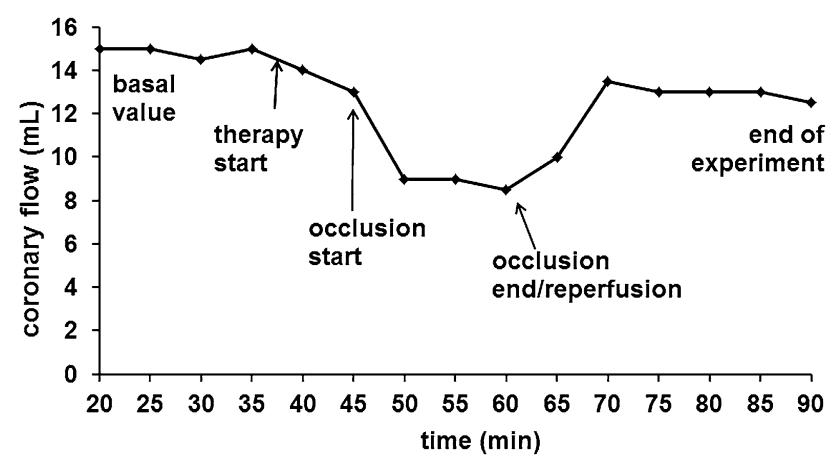

Fig. 1 Langendorff experiment design with liquid nitrogen and pestled for homogenization. For determination of the oxidizing parameters, $100 \mathrm{mg}$ quantities was mixed with $1 \mathrm{~mL}$ Tris buffer, vortexed, centrifuged and the supernatant was used for derivatization.

\section{Investigation of oxidative stress markers}

Liquid nitrogen frozen tissue samples (chicken and rat) were pestled for homogenization. $100 \mathrm{mg}$ of the obtained powder were mixed with $1 \mathrm{~mL}$ of $10 \mathrm{mM}$ Tris-HCl buffer $\mathrm{pH} 7.4$, centrifuged $\left(6500 \mathrm{rpm}, 4{ }^{\circ} \mathrm{C}, 30 \mathrm{~min}\right)$ and the supernatant was used for further investigation of both CPs and MDA. These experiments were carried out according to Russ et al. [18]. DNPH was applied for CP detection, TBA was used as reagent for MDA analysis. After preparation, every sample was investigated with HPLC/UV-Vis. External standards (DNPH, MDA) were daily freshly prepared and applied for accurate determination.

All experiments were carried out with 5 different hearts $(n=5)$ and determined twice. Results were calculated in $\mathrm{nmol} / \mathrm{g}$ tissue. Values of hearts without occlusion/hydrogen peroxide (= without oxidative stress) were set as $100 \%$. Values of tested hearts with occlusion/hydrogen peroxide (= exposure to oxidative stress) were compared and calculated as raise in \%. For statistical significance, the $p$ values were calculated as independent $T$ test samples with IBM Statistical Program of Social Sciences (SPSS) statistics 25 software. A $p$ value $<0.05$ was considered as statistically significant.

\section{Histological and immunohistochemical analysis}

After treatment of isolated rat hearts, the particular material was fixed in $10 \%$ neutrally buffered formalin and embedded in paraffin. From obtained blocks, $4-\mu \mathrm{m}$-thick sections were cut, stained with hematoxylin and eosin (HE), and immunohistochemically stained with antibodies against nitrotyrosine (A21285, 1:200, Thermo Fischer Scientific, Waltham, MA, USA) and 4-Hydroxynonenal (4-HNE) (ab46545, 1:200, AbCam, Cambridge, MA, USA).

Analysis of nitrotyrosine was performed using UltraView detection kit (Ventana Medical Systems, Inc., Tucson, AZ, USA) on Benchmark Ultra slide staining instrument (Ventana Medical Systems, Inc., Tucson, AZ, USA), after pre-treatment with $\mathrm{CC} 1$ for $80 \mathrm{~min}$. 3,3'-diaminobenzidine (DAB) substrate-chromogen was used for visualization. 4-HNE was stained on DAKO Autostainer (DAKO, Glostrup, Denmark), after pre-treatment with NatriumCitrat-Puffer pH 6.0 for 40 min at 150 Watt. EnVision Kit 5007 (DAKO, Glostrup, Denmark), and DAB were used for detection. Each immunostained section was analyzed and evaluated based on the average intensity of staining as: negative or positive (weak, intermediate or strong). 


\section{Results}

\section{Oxidative stress on isolated rat hearts}

Hearts treated with the diluted multi-component solution D20 showed an improvement after coronary artery occlusion compared to hearts treated with KRS. Functional parameters measured at the Langendorff experiment before occlusion and at the end of reperfusion (average of last $15 \mathrm{~min}$ of reperfusion) are summarized in Table 1. All standard deviations were $<13 \%$. Additionally, normal sinus rhythm in reperfusion was achieved faster when applying D20 solution (average 15 min KRS vs. 2 min D20).

In order to obtain information about oxidative stress through occlusion-resulting via myocardial infarction-and its effect occurring in the differently treated hearts (KRS, D20), MDA and CPs were studied. This procedure seems to be most appropriate for real life conditions. Both parameters were examined in the heart tissue with HPLC/ UV-Vis. As can be seen in Fig. 2, an increase of both parameters in hearts treated with KRS occurred. MDA showed a rise of about $160 \%$ through oxidative stress, CPs increased about $950 \%$ compared to hearts without oxidative stress. Treatment with D20 resulted in a MDA value that remained at the level of about $100 \%$, and an increase of about $260 \%$ CPs. MDA and CPs basal values for rat hearts were $18.64 \pm 0.76 \mathrm{nmol} / \mathrm{g}$ tissue and $2.16 \pm 0.34 \mathrm{nmol} / \mathrm{g}$ tissue, respectively.

For statistical significance, $p$ values were calculated by comparing KRS and D20. For MDA and CPs investigations, the $p$ value was found to be 0.001 and 0.013 , respectively. Furthermore, histological analysis of rat heart tissue treated with D20 or KRS and stained with HE showed in both cases myocytes with enlarged, focally centralized nuclei. Nevertheless, immunostainings with antibodies against 4-HNE and nitrotyrosine exhibited intermediate intensity of staining in KRS group, while the staining in D20 group was weak (Fig. 3). Note positive endothelial

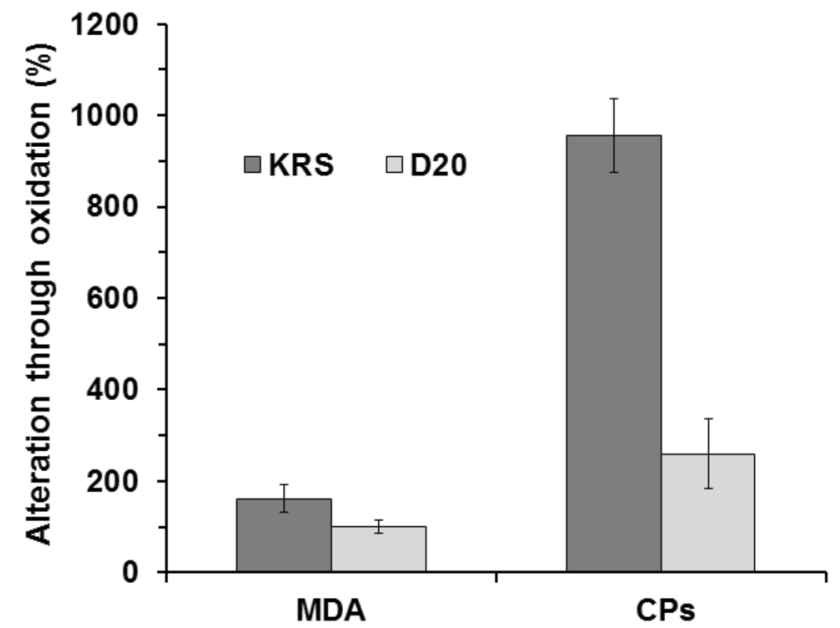

Fig. 2 Increase of oxidative stress markers in isolated rat hearts through occlusion of a coronary artery

cells in Fig. 3c and e (arrowhead) as positive internal control.

\section{Oxidative stress on chicken heart tissue}

Chicken hearts were oxidized with hydrogen peroxide and also examined considering the oxidative stress parameters MDA and CPs. Figure 4 displays a rise of MDA (about $190 \%$ ) and CPs (about 140\%) in hearts treated with KRS compared to non-oxidized tissue (=basal value). On the other hand, treatment with D20 led to an increase of about $120 \%$ MDA and no rise in CPs. For concentration studies, dilutions of 50\% (D50), 20\% (D20), and 5\% (D5) were examined. Figure 5 shows the outcome of these investigations. Single component studies were carried out at the same concentrations of ingredients as used in D50. Figure 6 displays the results of the single ingredient experiments. 5-HMF, NALM, and NASeLM treated hearts showed a rise of MDA between 200 and 350\% and an average similar rise of $150 \%$ considering CPs. In contrast, MDA and CPs levels in hearts treated with $\alpha-\mathrm{KG}$ remained the same as in hearts without additional hydrogen peroxide treatment (= without
Table 1 Functional assessment of the hearts subjected to ischemia reperfusion injury

\begin{tabular}{lccccc}
\hline & Heart rate $(\mathrm{bpm})$ & $\mathrm{LVDP}(\mathrm{mmHg})$ & $\begin{array}{c}+\mathrm{dP}_{\mathrm{dt}} \max \\
(\mathrm{mmHg} / \mathrm{s})\end{array}$ & $\begin{array}{l}-\mathrm{dP}_{\mathrm{dt}} \text { max } \\
(\mathrm{mmHg} / \mathrm{s})\end{array}$ & $\begin{array}{l}\text { Coronary } \\
\text { flow }(\mathrm{mL} / \\
\mathrm{min})\end{array}$ \\
\hline KRS & & & & & \\
Before occlusion & 287.40 & 100.72 & 3718.47 & 2243.75 & 15.42 \\
End of reperfusion & 505.40 & 66.73 & 2973.45 & 1584.85 & 15.05 \\
D20 & & & & & \\
Before occlusion & 269.63 & 102.62 & 3632.87 & 2255.50 & 14.46 \\
End of reperfusion & 203.66 & 97.19 & 3166.59 & 1829.17 & 15.75 \\
\hline
\end{tabular}


Fig. 3 Comparison of histological and immunohistochemical findings. HE staining: D20 group (a) and KRS group (b); 4-HNE-staining: D20 group (c) and KRS group (d); nitrotyrosine staining: D20 group (e) and KRS group (f). Note positive endothelial cells in $\mathrm{C} \& \mathrm{E}$ (arrowhead) as positive internal control. Original magnification $\times 400$
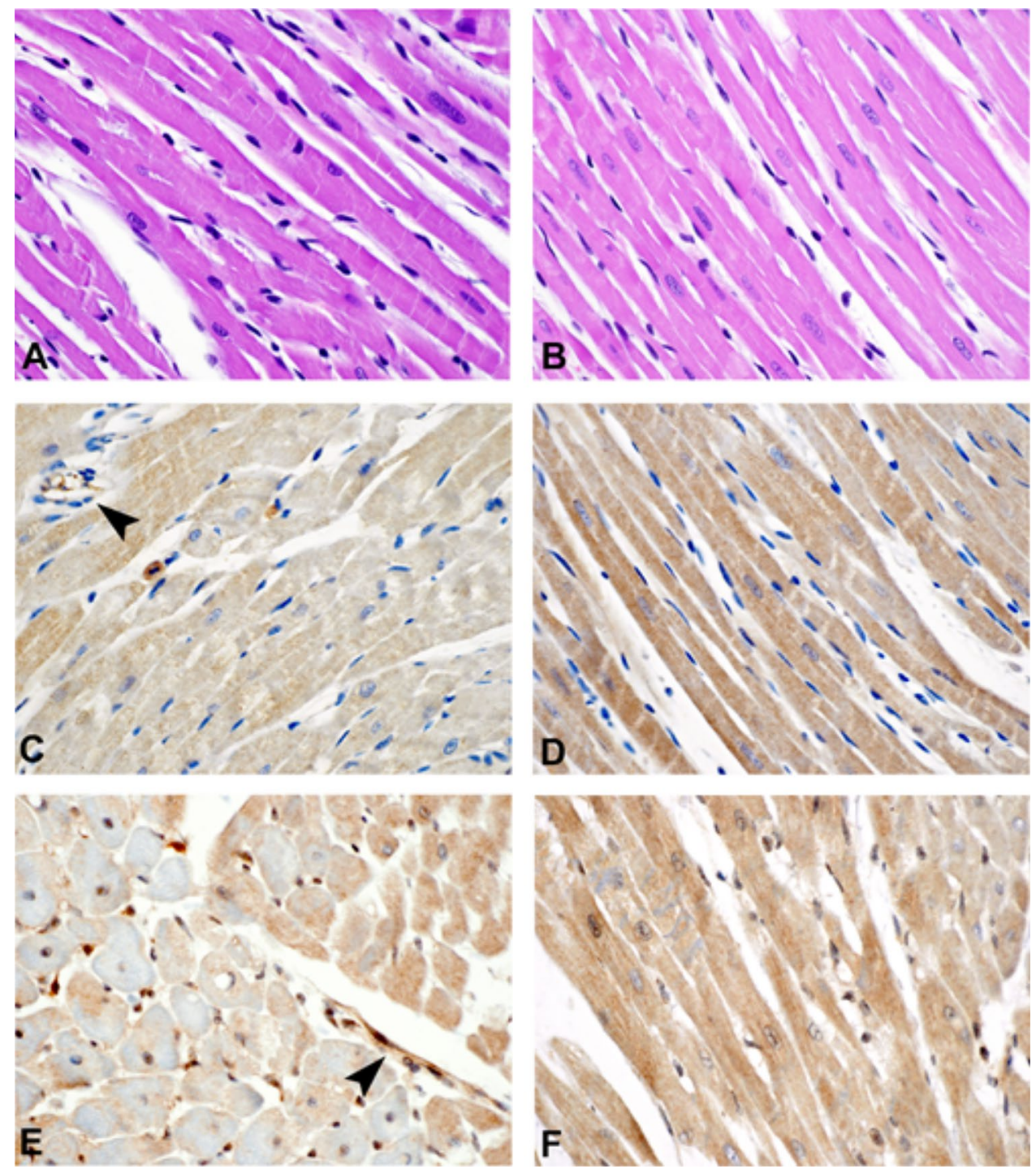

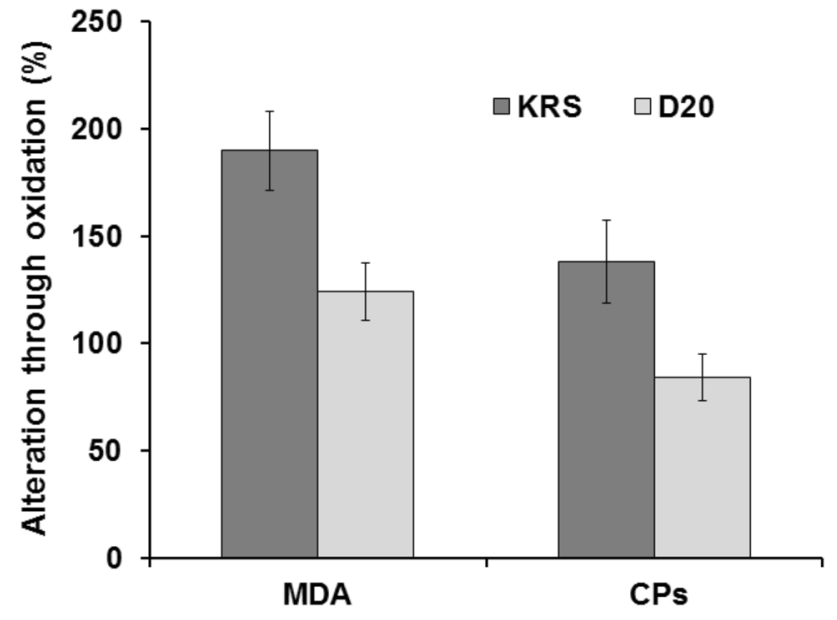

Fig. 4 Increase of oxidative stress markers in chicken heart tissue through treatment with $5 \%$ hydrogen peroxide

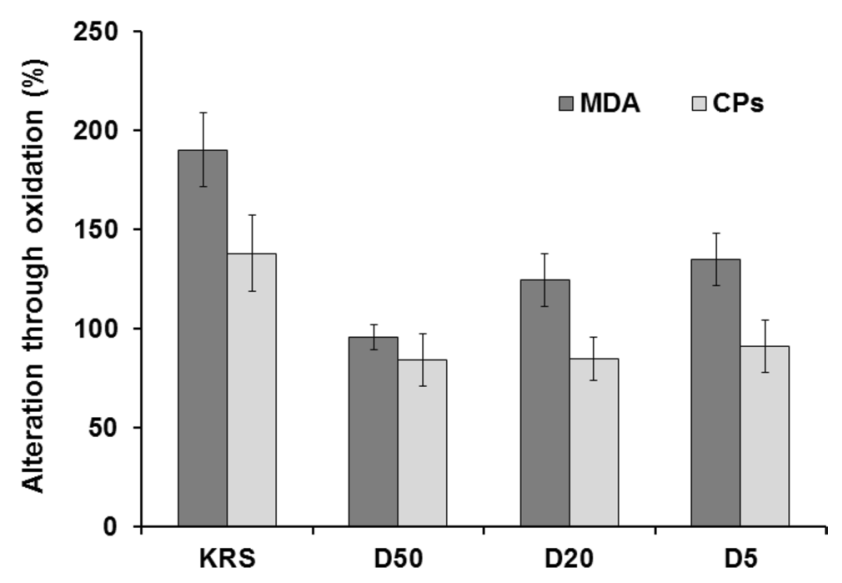

Fig. 5 Influence of different concentration solutions and 5\% hydrogen peroxide on oxidative stress markers in chicken heart tissue 


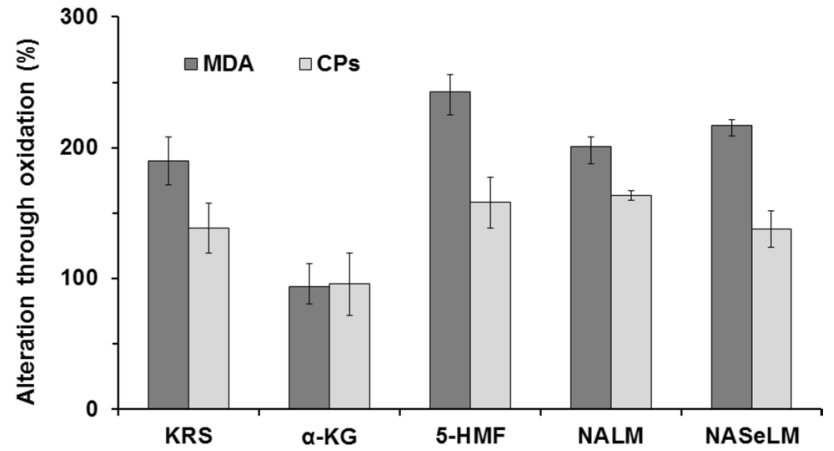

Fig. 6 Influence of single ingredient solutions and 5\% hydrogen peroxide on oxidative stress markers in chicken heart tissue

oxidative stress). The relevance of the performed studies can be seen from the statistical data given in Table 2 .

\section{Discussion}

Herein, a supposed antioxidative effect of a multi-component solution against ROS occurring through oxidative stress in heart tissue was examined via MDA and CPs determination. The parameters MDA and CPs cover the field of oxidative protein and lipid damage and therefore provide meaningful information on cell decay of cardiomyocytes. Oxidative stress was induced either through myocardial infarction or through application of hydrogen peroxide.

Isolated rat hearts were examined on a Langendorff device. The therapeutic approach of D20 was applied for this study because of former experiments [13]. All Langendorff observations indicate a positive influence of D20 during ischemia/oxidative stress. This effect was also confirmed in immunostaining experiments by means of detecting 4-HNE and nitrotyrosine. Considering the investigated oxidative stress parameters, D20 reduced MDA and CPs in these experiments with a significance of $p<0.05$ compared to a negative control. The same trend was found in chicken heart tissue studies.

For further analysis, commercially available chicken heart tissue was used in order to avoid material directly from living animals for the described purpose. Experiments were carried out regarding concentration and single components of the tested solution.

At concentration studies, MDA levels were lower at all concentrations compared to the negative control with KRS. The effect seems to be slightly concentration dependent with a result of no rise with D50 treated hearts, and a rise of about $120 \%$ and $130 \%$ for D20 and D5 treated hearts. Considering $\mathrm{CPs}$, all concentrations revealed a similar result with no rise compared to non-oxidized tissue.

Single component studies were carried out at the same concentrations of ingredients as used in D50 because of the best influence of this concentration as given above. The results of these experiments identify $\alpha-K G$ as effective antioxidative ingredient of the tested solution in chicken heart tissue which is treated with hydrogen peroxide. All other ingredients seem to have less/no antioxidative effect in these experiments. Although 5-HMF is reported to have antioxidative effects $[7,8,19]$ even in liver tissue $[20,21]$, this failed to proof under oxidizing conditions in chicken heart tissue. $\alpha-K G$ is known for its antioxidative effect for example in fruit flies [22, 23]. According to the review of Zdzisinksa et al., it inhibited oxidative stress through ammonium acetate and ethanol in vivo in rats and showed positive antioxidative effects during hepatocarcinogenesis and cataract formation [6]. In the body it plays a role in the citrate cycle and is reported to react directly with hydrogen peroxide, forming carboxylic acid, $\mathrm{CO}_{2}$, and $\mathrm{H}_{2} \mathrm{O}[5,6]$. However, it has never been studied considering this effect in heart tissue exposed to oxidative stress before.

Overall, the results of this study showed that the multicomponent solution exhibited an antioxidative effect against the induced oxidative stress. Both investigated parameters were increased through oxidative stress in the control group,
Table 2 Statistical data of investigations in chicken heart tissue

\begin{tabular}{lclll}
\hline & MDA nmol/g tissue & $\begin{array}{l}p \text { value (compared } \\
\text { to KRS) }\end{array}$ & CP nmol/g tissue & $\begin{array}{l}p \text { value } \\
\text { (compared to } \\
\text { KRS) }\end{array}$ \\
\hline Basal value & $47.45 \pm 2.85$ & & $1.83 \pm 0.30$ & \\
KRS & $90.08 \pm 16.76$ & & $2.53 \pm 0.48$ & \\
D20 & $58.96 \pm 7.81$ & 0.015 & $1.54 \pm 0.17$ & 0.009 \\
D50 & $45.24 \pm 2.91$ & 0.002 & $1.54 \pm 0.20$ & 0.009 \\
D5 & $63.94 \pm 8.51$ & 0.032 & $1.66 \pm 0.22$ & 0.016 \\
$\alpha-$ KG & $44.42 \pm 7.97$ & 0.003 & $1.75 \pm 0.42$ & 0.049 \\
$5-H M F$ & $115.28 \pm 15.35$ & 0.068 & $2.89 \pm 0.56$ & 0.357 \\
NALM & $95.31 \pm 7.31$ & 0.588 & $2.99 \pm 0.11$ & 0.112 \\
NASeLM & $102.85 \pm 5.09$ & 0.195 & $2.52 \pm 0.35$ & 0.986 \\
\hline
\end{tabular}


but stayed at basal level or were less increased through application of the multi-component solution. Additionally, $\alpha-K G$ was identified as antioxidative component in chicken heart tissue in these experiments. Nevertheless, metabolic processes might influence the effectivity of the different ingredients in vivo. Therefore, all ingredients of the multicomponent solution (single and together) may exhibit a positive effect against oxidative stress. In order to identify these possible effects, in vivo studies are planned.

Up to now, only few solutions are available for organ transplantations. The approach described in this study is novel and seems to be a powerful option to be transferred for heart transplantations in order to improve shelf life and avoid graft failure.

Acknowledgements Open access funding provided by University of Graz.

\section{Compliance with ethical standards}

Conflict of interest The authors declare that they have no conflict of interest.

Research involving human and animals rights All applicable international, national, and institutional guidelines for the care and use of animals were followed

Open Access This article is distributed under the terms of the Creative Commons Attribution 4.0 International License (http://creativeco mmons.org/licenses/by/4.0/), which permits unrestricted use, distribution, and reproduction in any medium, provided you give appropriate credit to the original author(s) and the source, provide a link to the Creative Commons license, and indicate if changes were made.

\section{References}

1. Goswami SK, Maulik N, Das DK (2007) Ischemia-reperfusion and cardioprotection: a delicate balance between reactive oxygen species generation and redox homeostasis. Ann Med 39:275-289. https://doi.org/10.1080/07853890701374677

2. Zhou T, Chuang C-C, Zuo L (2015) Molecular characterization of reactive oxygen species in myocardial ischemia-reperfusion injury. Biomed Res Int 2015:1-9. https://doi.org/10.1155/2015/864946

3. Han J, Wang D, Yu B, Wang Y, Ren H, Zhang B, Wang Y, Zheng $\mathrm{Q}$ (2014) Cardioprotection against ischemia/reperfusion by licochalcone B in isolated rat hearts. Oxid Med Cell Longev 2014:1-11. https://doi.org/10.1155/2014/134862

4. Rjiba-Touati K, Ayed-Boussema I, Guedri Y, Achour A, Bacha H, Abid-Essefi S (2015) Effect of recombinant human erythropoietin on mitomycin $\mathrm{C}$-induced oxidative stress and genotoxicity in rat kidney and heart tissues. Hum Exp Toxicol 35:53-62. https://doi. org/10.1177/0960327115577521

5. Liu S, He L, Yao K (2018) The antioxidative function of alphaketoglutarate and its applications. Biomed Res Int 2018:3408467. https://doi.org/10.1155/2018/3408467

6. Zdzisińska B, Żurek A, Kandefer-Szerszeń M (2017) Alphaketoglutarate as a molecule with pleiotropic activity: well-known and novel possibilities of therapeutic use. Arch Immunol Ther Exp 65:21-36. https://doi.org/10.1007/s00005-016-0406-x
7. Shapla UM, Solayman M, Alam N, Khalil MI, Gan SH (2018) 5-Hydroxymethylfurfural (HMF) levels in honey and other food products: effects on bees and human health. Chem Cent J 12:35. https://doi.org/10.1186/s13065-018-0408-3

8. Zhao L, Chen J, Su J, Li L, Hu S, Li B, Zhang X, Xu Z, Chen $T$ (2013) In vitro antioxidant and antiproliferative activities of 5-hydroxymethylfurfural. J Agric Food Chem 61:10604-10611. https://doi.org/10.1021/jf403098y

9. Zolali E, Hamishehkar H, Maleki-Dizaji N, Majidi Zolbanin N, Ghavimi H, Kouhsoltani M, Asgharian P (2014) Selenium effect on oxidative stress factors in septic rats. Adv Pharm Bull 4:289 293. https://doi.org/10.5681/apb.2014.042

10. Duntas LH, Benvenga S (2015) Selenium: an element for life. Endocrine 48:756-775. https://doi.org/10.1007/s1202 0-014-0477-6

11. Martínez Y, Li X, Liu G, Bin P, Yan W, Más D, Valdivié M, Hu C-AA, Ren W, Yin Y (2017) The role of methionine on metabolism, oxidative stress, and diseases. Amino Acids 49:2091-2098. https://doi.org/10.1007/s00726-017-2494-2

12. Colovic MB, Vasic VM, Djuric DM, Krstic DZ (2018) Sulphurcontaining amino acids: protective role against free radicals and heavy metals. Curr Med Chem 25:324-335. https://doi. org/10.2174/0929867324666170609075434

13. Schwarz M, Greilberger J, Lamacie M, Wasler A, Wintersteiger R, Lang I, Santos RAS (2012) Alpha-ketoglutarate, 5-hydroxymethylfurfurale and Angiotensin 1-7: cardioprotective effects during myocardial ischemia/reperfusion. Can J Cardiol 28:132. https ://doi.org/10.1016/j.cjca.2012.07.123

14. Pachauri P, Garabadu D, Goyal A, Upadhyay PK (2017) Angiotensin (1-7) facilitates cardioprotection of ischemic preconditioning on ischemia-reperfusion-challenged rat heart. Mol Cell Biochem 430:99-113. https://doi.org/10.1007/s11010-017-2958-4

15. Ferreira AJ, Santos RAS, Almeida AP (2002) Angiotensin-(1-7) improves the post-ischemic function in isolated perfused rat hearts. Braz J Med Biol Res 35:1083-1090. https://doi. org/10.1590/S0100-879X2002000900009

16. Ferreira AJ, Santos RAS, Almeida AP (2001) Angiotensin-(1-7): cardioprotective effect in myocardial ischemia/reperfusion. Hypertension 38:665-668. https://doi.org/10.1161/01.HYP.38.3.665

17. Marrocco I, Altieri F, Peluso I (2017) Measurement and clinical significance of biomarkers of oxidative stress in humans. Oxid Med Cell Longev 2017:6501046. https://doi. org/10.1155/2017/6501046

18. Russ M, Weinheimer L, Jauk S, Andrä M, Wintersteiger R, Ortner A (2019) Characterization of oxidative stress in chicken heart tissue by high-performance liquid chromatography with ultravioletvisible (HPLC-UV-Vis) detection. Anal Lett 52:892-901. https ://doi.org/10.1080/00032719.2018.1505899

19. Li YX, Li Y, Qian ZJ, Kim MM, Kim SK (2009) In vitro antioxidant activity of 5-HMF isolated from marine red alga Laurencia undulata in free-radical-mediated oxidative systems. J Microbiol Biotechn 19:1319-1327. https://doi.org/10.4014/jmb.0901.0004

20. Li W, Qu X-N, Han Y, Zheng S-W, Wang J, Wang Y-P (2015) Ameliorative effects of 5-hydroxymethyl-2-furfural (5-HMF) from Schisandra chinensis on alcoholic liver oxidative injury in mice. Int J Mol Sci 16:2446-2457. https://doi.org/10.3390/ijms1 6022446

21. Han X-Y, Hu J-N, Wang Z, Wei S-N, Zheng S-W, Wang Y-P, Li W (2017) 5-HMF attenuates liver fibrosis in CCl4-plus-alcoholinduced mice by suppression of oxidative stress. J Nutr Sci Vitaminol 63:35-43. https://doi.org/10.3177/jnsv.63.35

22. Bayliak MM, Lylyk MP, Vytvytska OM, Lushchak VI (2016) Assessment of antioxidant properties of alpha-keto acids in vitro and in vivo. Eur Food Res Technol 242:179-188. https://doi. org/10.1007/s00217-015-2529-4 
23. Bayliak MM, Shmihel HV, Lylyk MP, Vytvytska OM, Storey JM, Storey KB, Lushchak VI (2015) Alpha-ketoglutarate attenuates toxic effects of sodium nitroprusside and hydrogen peroxide in Drosophila melanogaster. Environ Toxicol Pharmacol 40:650 659. https://doi.org/10.1016/j.etap.2015.08.016
Publisher's Note Springer Nature remains neutral with regard to jurisdictional claims in published maps and institutional affiliations. 